\section{Managing Children with Special Needs in COVID-19 Times}

Children with special needs are facing additional predicament of understanding and dealing with the challenges brought about by the ongoing pandemic due to their unique health conditions. We herein, underscore some of the important issues.

Challenges: Interruption of requisite therapies can have longterm consequences on children with developmental disabilities. Cessation of regular physiotherapy may worsen functional ability and cause complications like hip dysplasia in children with cerebral palsy [1]. Lack of a daily schedule can be challenging for children with autism who require reliable routines, resulting in irritability and temper tantrums. Lack of understanding of the effects of pandemic, resistance to change and inability to adapt to new strategies can lead to pre-existing behavioral problems intensifying or development of novel ones in these children, especially those with autism and intellectual disability. Children with attention deficit and hyperactivity disorder (ADHD) and learning disorder may not be able to make effective use of online school sessions due to poor attention span or difficulty in comprehension [2]. Additionally, children with disabilities are at a greater risk of contracting Covid-19 because of their health-related challenges and inability to understand and follow recommended measures for infection control $[3,4]$.

Parents of these children are also facing tough times. Their children's health related stress, which was earlier shared between parents, schools and therapy centers, has to be dealt with by them alone. Perception of delay in child's progress, inaccessibility to remedial services along with economic constraints due to lockdown and inability to engage children in activities throughout the day may impose a huge mental burden. Thus, mental health counselling for parents is an additional intervention required.

Suggestions for care: Since children with special needs may not be able to follow the standard respiratory etiquette like wearing of masks and social distancing due to their health conditions and behavioral issues, parents can create a circle of protection for their children by stringently following safety measures. Visual charts for hand hygiene and social distancing may help children with autism and intellectual disability. For children with visual impairment clear verbal instructions along with physical prompts can help [4]. Along with this, disinfection of the adaptive devices like wheelchairs, orthotics, hearing aids etc. should be stressed upon.

Parents should try to maintain some schedule for their children by following online school sessions and engaging them in fun based household chores. Wherever possible, these children should be encouraged to continue social interaction through supervised telephonic and video calls. Avoiding extra demands and unrealistic expectation from children during these times may help in eluding frustration and behavioral issues.

As far as possible, clinical focus of specialised treatment should shift to telehealth services and 'virtual first' approach must remain standard practice [5]. Tele-intervention is a viable service model for continuing intervention in children with disabilities. Apart from questionnaire-based assessments and guided therapies, it can be helpful for giving psychological support to the families and thus reduce chances of abuse and neglect.

To summarize, during the current pandemic when accessibility to essential services is difficult, children with disabilities and their parents are a high-risk group for various physical and mental health issues, and need appropriate guidance and support.

Published online: July 24, 2020; PII: S097475591600213.

$$
\begin{array}{r}
\text { Monica JUNEJA AND ARPITA GUPTA* } \\
\text { Department of Pediatrics, } \\
\text { MaulanaAzad Medical College, NewDelhi, India. } \\
\text { *arpita1517@gmail.com }
\end{array}
$$

\section{REFERENCES}

1. Ben-pazi H, Beni-adani L, Lamdan R. Accelerating telemedicine for cerebral palsy during the COVID-19 pandemic and beyond. Front Neurol. 2020;11:1-7.

2. UNESCO. Life in the Times of COVID. A Guide for Parents with Special Needs. Available from: https:// en.unesco.org/sites/default/files/final_parents_guide_ covid_19_fn.pdf. Accessed June 29, 2020.

3. Indian Council of Medical Research. Guidance Document for Health System Response for Persons with Disabilities and Functional Impairment During Pandemic i.e. COVID19. Available from: https://www.scdisabilities.org/resource $/ P W D$ first\%20final.pdf. Accessed June 30, 2020.

4. WHO Disability considerations during the COVID-19 outbreak. Available from:https://www.who.int/publications/ i/item/disabilityconsiderations-during-the-covid-19 outbreak. Accessed June 5, 2020.

5. Mahajan V, Singh T, Chandrika V. Using telemedicine during the COVID-19 pandemic. Indian Pediatr. 2020;57:652-57. 